\title{
The effect of $\beta$-carotene and nucleotide base supplementation on haematological, biochemical and certain immunological parameters in weaned pigs*
}

\section{Melinda Zomborszky-Kovács ${ }^{1}$, S. Tuboly², H. Bíró ${ }^{1}$, L. Bárdos ${ }^{3}$, P. Soós ${ }^{2}$, Á.Tóth' and G. Tornyos'}

\author{
'Pannon University of Agriculture, Faculty of Animal Science \\ 7400 Kaposvár, Hungary \\ 'University of Veterinary Science \\ P.O. Box 2, 1400 Budapest. Hungary \\ ${ }^{3}$ Gödöllö University of Agriculture, Department of Animal Physiology \\ $H$-2103 Gödöllö, Hungary
}

\section{ABSTRACT}

The effect of synthetic $\beta$-carotene and of synthetic nucleotide bases was investigated in this experiment. Beginning one week prior to weaning, the diet fed to one experimental group of piglets was supplemented with $10 \%$ Rovimix $\beta$-carotene at $875 \mathrm{mg} / \mathrm{kg}$ diet $(10$ times the recommendation of the NRC, 1988). Synthetic uracil and adenine (98\%, Sigma-Aldrich) were mixcd into the diet for the other experimental group at quantities of $500 \mathrm{mg} / \mathrm{kg}$ diet of each substance. During the 3 -week period of the experiment changes in the daily weight gain of the animals, their feed consumption and certain blood parameters were examined. Changes which could be observed with the progress of time in the haematological parameters (RBC, WBC, Hb, HTC, MCV, MCH, MCHC), in the ESR and in certain biochemical parameters (TP, ALB, CHOL, TRIG, UREA, ALT and AST) can be regarded as physiological. The LST values given for Phytohaemagglutinin and Concanavalin-A increased in the experimental groups by 50 and $130 \%$, respectively (nucleotide), and by 60 and $30 \%$, respectively, (carotene) respectively, while the blastic transformation of the lymphocytes did not vary in the control group. The supplements applicd exerted no positive effect on in vivo cellular immune response. No significant degree of difference was observed between the plasma retinol concentrations determined at the end of the experimental period, (control: $376+183$, nucleotide: $412 \pm 268$ and carotene: $349 \pm 251 \mu \mathrm{g} / \mathrm{L}$ ) while there was a decrease in plasma E-vitamin concentration due to carotene supplementation (control: $5.58 \pm 2.36$, nucleotide: $5.83+3.01$ and carotene: $2.12 \pm 1.60 \mathrm{mg} / \mathrm{L}$ ).

KEY WORDS: nucleotide bases, beta-carotene, immune response, piglets

* Financial support for this research project was provided by the Foundation for Higher Education and Research in Hungary (project no. AMFK 137/96) 


\section{INTRODUCTION}

It is a generally known fact that there is a relation between stress conditions, the immune responsiveness of an animal and certain frequently occurring disorders (Kelley, 1980; Sicgel, 1985; Blecha, 1988). In such cases stimulation of the immune response may manifest itself in the form of an increase in resistance to disease in animals.

A number of chemical substances (levamisol, imuthiol, avridine, isoprinosine, etc.) are known to exert a stimulating effect on the functioning of the immune system (Kende et al., 1984; Torrence, 1985; Blecha, 1988). Due to reservations about the application of such non-endogenous chemical substances attention has now turned to the determination of the immunomodulatory effect of, and possibilities for the application of, substances occurring in the organism even under natural conditions (vitamins, minerals, amino acids, etc.).

The present experiment investigated the effects of dietary supplementation with synthetic $\beta$-carotene and synthetic nucleotide bases on immune system function in the piglet.

\section{MATERIAL AND METHODS}

\section{Animals}

Unweaned 20-to-22-day-old piglets were divided into three groups such that 6 healthy piglets of approximately identical weight, taken from two litters, were selected for cach group (12 per group). Feeding with the experimental diets was initiated 7 days prior to weaning; subsequently, after removal from the litters the animals were housed together in batteries, in which they were fed the experimental diets for a further two weeks. The state of health of the animals (the frequency and severity of diarrhoea and the number of days for which the animals were affected by this) was monitored, and the quantity of feed consumed per group and individual body weight gain were recorded.

\section{Feeding}

The basic diet of one of the experimental groups was supplemented with $10 \%$ Rovimix Beta-carotene (Hoffmann-La Roche, $100 \mathrm{mg} / \mathrm{g} \beta$-carotene) at $875 \mathrm{mg} / \mathrm{kg}$ diet (10 times the recommendation of the NRC, 1988). Synthetic uracil and adenine $(98 \%$, Sigma-Aldrich) were mixed into the diet for the other experimental group at quantities of $500 \mathrm{mg} / \mathrm{kg}$ dict of each substance. 


\section{Collection of samples}

Blood samples were taken from the vena cava cranialis on the 1 st, 7 th and 21 st day of the experimental period into two tubes containing dipotassium ethylendiamine tetraacetate (K-EDTA) and sodium-heparin, respectively.

\section{Haematological analyses}

Cobas Minos STE equipment (Roche, Switzerland) was used to determine the concentration of red blood cells (RBC), white blood cells (WBC) and haemoglobin (Hb), haematocrit value (HTC), mean corpuscular volume (MCV), mean corpuscular haemoglobin $(\mathrm{MCH})$ and mean corpuscular haemoglobin concentration (MCHC). Erythrocyte sedimentation rate (ESR) was also determined, in accordance with the method described by Westergreen (Horwath, 1979).

\section{Biochemical parameters}

Determination of total protein (TP), albumin (ALB), globulin (GLOB), blood urea nitrogen (BUN), cholesterol (CHOL), triglyceride (TG) and uric acid (UA) concentration in blood plasma was performed by means of a Centrifichem 600 analyser (Roche), while gamma glutamyl transferase (GGT), aspartic acid aminotransferase (AST) and alanine aminotransferase (ALT) activity determination involved the use of a Kodak Ectachem $750 \mathrm{x}$ rc analyser with Johnson and Johnson test discs.

\section{Immunological parameters}

In order to investigate in vitro cellular immune responsiveness an examination of blastic transformation, induced by means of 200 gamma per ml Phytohaemagglutinin (PHA) or Concanavalin-A (Con A), was performed, by application of the lymphocyte stimulation test (LST). The rate of the blastogenic response was determined by fluorometric DNA assay (Nagahata et al., 1987).

The in vivo cellular immunc response was examined by means of an intradermal probe. $0.1 \mathrm{ml}$ of the PHA solution (500 mg Phytohaemagglutinin M dissolved in $1 \mathrm{ml}$ PBS) was injected into the skin of the neck on the last day of the experiment. Skin fold thickness was measured at $24 \mathrm{~h}$ post-injection.

\section{Statistical analysis}

The various statistical analyses made were performed by application of the SPSS programme package (1996); in this, differences between the groups and 
between blood samplings were examined by means of paired t-test and variance analysis.

\section{RESULTS AND DISCUSSION}

Subsequent to weaning (on days 7 to 21 of the experimental period) the more intensive body weight gain observed in the groups fed the experimental diets was assumed to be due to their higher feed consumption (Table 1).

TABLE 1

The influence of $\beta$-Carotene and nucleotide supplementation on body weight gain (means \pm SD) and feed consumption

\begin{tabular}{clcc}
\hline Period investigated & Groups & $\begin{array}{r}\text { Feed consumption } \\
\mathrm{kg} / \text { group }\end{array}$ & $\begin{array}{c}\text { Body weight gain, kg } \\
(\mathrm{x} \pm \mathrm{SD})\end{array}$ \\
\hline \multirow{2}{*}{$0-7$ days } & Control & 5.1 & $1.65^{\mathrm{x}} \pm 0.56$ \\
& Carotene & 4.3 & $1.16^{\mathrm{y}} \pm 0.16$ \\
& Nucleotide & 3.9 & $1.60^{\mathrm{x}} \pm 0.36$ \\
7 7-21 days & Control & 47.2 & $2.37^{\mathrm{x}} \pm 0.62$ \\
& Carotene & 56.9 & $3.74^{\mathrm{y}} \pm 0.85$ \\
& Nucleotide & 57.3 & $3.33^{\mathrm{xy}} \pm 1.58$ \\
\hline
\end{tabular}

note: superscripts denote significant $(\mathrm{P}<0.05)$ differences between groups

Of the hacmatological parameters, RBC and WBC count were observed to increase with time. $\mathrm{MCH}$ and $\mathrm{MCV}$ values decreased in all three groups. ESR increased in the control animals (from 1.9 to $3.4 \mathrm{mM} / \mathrm{h}$ ), while showing a decrease by the 3rd blood sample $(\mathrm{P}<0.05)$ in both experimental groups (carotene from 2.5 to 1.5 , nucleotide from 2.3 to $1.2 \mathrm{mM} / \mathrm{h}$ ). These changes, observed with the progress of time, can be regarded as physiological (Schalm, 1986). Neither carotene nor nucleotide supplementation exerted any significant effect on the parameters studied.

With respect to the biochemical parameters examined, a decrease, within the physiological limit values, was observed in TP, ALB, CHOL and TRIG concentration with the passage of time, while BUN concentration was seen to increase, as was AST and ALT activity. There was no substantial change in the quantity of uric acid present. In the group fed the diet supplemented with carotene, lower CHOL concentration $(\mathrm{P}<0.001)$ and GGT activity $(\mathrm{P}<0.001)$ was measured in comparison with that of the control group.

The LST values given for PHA and Con A increased in the experimental groups by 50 and $130 \%$, respectively (nucleotide), and by 60 and $30 \%$, respectively, (carotene), while the blastic transformation of the lymphocytes did not vary in the control group. In both groups the response for PHA was of a greater degree than the reaction elicited by Con A (Table 2). 
TABLE 2

Changes in the LST values (\%) after stimulation of the lymphocytes with PHA and ConA and the results of the intradermal PHA test (means + S.D.)

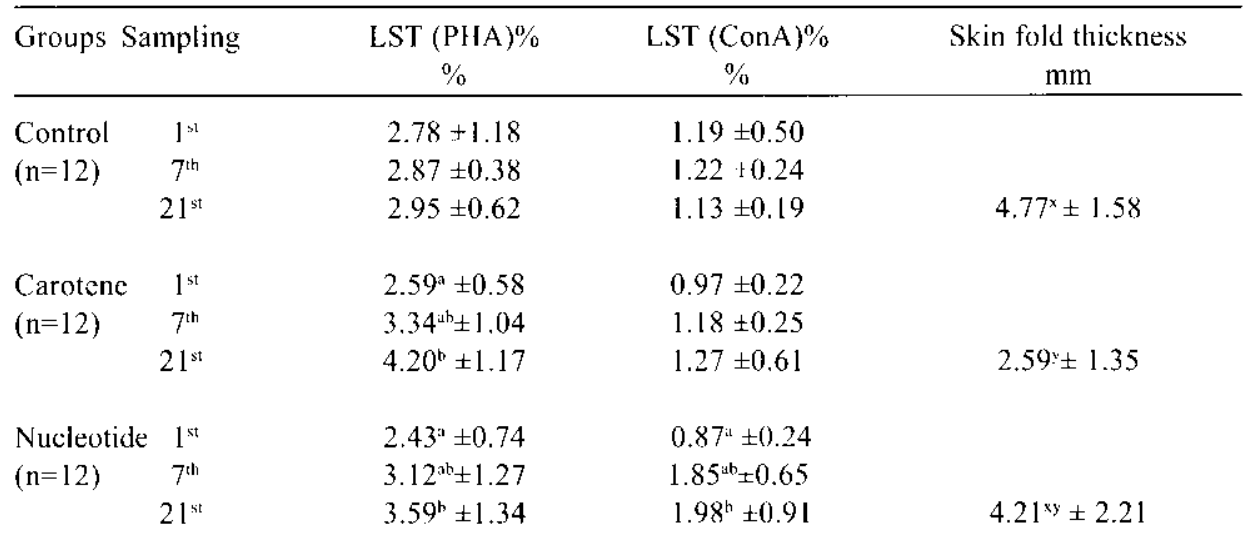

note: different superscripts $(a, b, c)$ denote significant $(\mathrm{P}<0.05)$ differences between blood samples and $(x, y)$ between groups

The two T-cell mitogens reflect the general cellular immune responsiveness of the organism. The results of this experiment correspond to data given in a number of reports in the literature, according to which both nucleotide and $\beta$-carotene supplementation result in an increase in T-cell immune responsiveness (Bendich and Shapiro, 1986; Barankiewicz and Cohen, 1987; Pérignon et al., 1987; Hoskinson et al., 1989; Daniel et al., 1991 a,b; Michal et al., 1994). $\beta$-carotene is deposited in the lymphocytes, and acts as an immunostimulator partly by virtue of its effect on membrane protection and partly via promoting blastogenesis (Chew ct al., 1993). Exogenous nucleotides and purine/pyrimidine bases also bring about an increase in cellular immune response, since, by forming a pool, they have the capacity to fulfil the increased requirements, with respect to metabolism and nucleic acid synthesis, of proliferation and blastogenesis (Carver, 1994).

No positive effect on in vivo cellular immune response was found with the supplements applied in this study, presumably due to the low concentration in which they were administered. The reason that the cutancous reaction observed in the group given $\beta$-carotene was of a lower degree than that produced in the control group and in the group given nucleotides may be that a negative effect was exerted on the level of vitamin $E$ by $\beta$-carotene or by vitamin $A$ formed from it. That is, at the time at which the intradermal test examination was performed, the concentration of vitamin $E$, which exerts a similar stimulatory effect on the functioning of the immune system, was in this group lower than half of that of the mean for the other two groups (Table 3 ). $\beta$-carotene was not detectable in the plasma even of the animals in the group consuming the carotene-supplemented diet. No significant differences were observed between the plasma retinol concentrations in the 
TABLE 3

Changes in serum vitamin-E concentrations $(\mathrm{mg} / \mathrm{L})$ (means \pm S.D.) following $\beta$-carotene or nucleotide supplementation

\begin{tabular}{cccc}
$\begin{array}{c}\text { Sampling } \\
\text { days }\end{array}$ & $\begin{array}{c}\text { Control } \\
\mathrm{n}=12\end{array}$ & $\begin{array}{c}\text { Carotene } \\
\mathrm{n}=12\end{array}$ & $\begin{array}{c}\text { Nucleotide } \\
\mathrm{n}=12\end{array}$ \\
\hline $7^{\mathrm{th}}$ & $2.32^{\mathrm{ax}} \pm 1.15$ & $2.76^{\mathrm{x}} \pm 1.09$ & $3.66^{\mathrm{ay}} \pm 2.05$ \\
$21^{\mathrm{st}}$ & $5.58^{\mathrm{bx}} \pm 2.36$ & $2.12^{\mathrm{y}} \pm 1.60$ & $5.83^{\mathrm{by}} \pm 3.01$ \\
\hline
\end{tabular}

note: superscripts $(a, b)$ denote significant $(P<0.05)$ differences between blood samples and $(x, y, z)$ between groups

different groups determined at the end of the experimental period (control $376 \pm 183$, nucleotide $412 \pm 268$ and carotene $349 \pm 251 \mathrm{mg} / \mathrm{L}$ ). Thus, the level of vitamin $\mathrm{A}$ in the plasma was not altered by the excess carotene dosed into the diet.

\section{REFERENCES}

Barankiewicz J., Cohen A., 1987. Purine nucleotide metabolism in phytohemagglutinin-induced human T lymphocytes. Arch. Biochem. Biophys. 258, 167-175

Bendich A., Saphiro S.S., 1986. Effect of 3 -carotene and canthaxanthin on immune responses of the rat. J. Nutr. 116, 2254-2262

Biesalski H., Greiff H., Brodda K., Hafner G., Bassler K.H., 1986. Rapid determination of vitamin A (retinol) and vitamin $\mathrm{E}$ (a-tocopherol) in human serum by isocratic adsorption HPLC. Int. J. Vit. Nutr. Res. 56, 319-327

Blecha F., 1988. Immunomodulation: A means of disease prevention in stressed livestock. J. Anim. Sci. $66,2084-2090$

Carver J., 1994. Dietary nucleotides: Cellular immune, intestinal and hepatic system effects. J. Nutr. $124,144 \mathrm{~S}-148 \mathrm{~S}$

Chew B.P., Wong T.S., Michal J.J., 1993. Uptake of orally administered $\beta$-carotene by blood plasma, leukocytes, and lipoproteins in calves. J. Anim. Sci. 71, 730-739

Danicl L.R., Chew B.P., Tanaka T.S., Tjoelker L.W., 1991a. $\beta$-carotene and vitamin A effects on bovine phagocyte function in vitro during the peripartum period. J. Dairy Sci. 74, 124-131

Danicl L.R., Chew B.P., Tanaka T.S., Tjoelker L.W., I991b. In vitro effects of ß-carotene and vitamin A on peripartum bovine peripheral blood mononuclear cell proliferation. J. Dairy Sci. 74, 911-915

Iforvath Z., 1979. Veterinarian Clinical Chemistry (in Hungarian). Mg Kiado, Budapest, pp. 101

Hoskinson C.D., Chew B.P., Wong T.S., 1989. Effects of $\beta$-catotene (BC) and vitamin A (VA) on mitogen-induced lymphocyte proliferation in the pig in vivo. FASEB J. 3, A663

Kelley K.W., 1980. Stress and immune function: A bibliographic review. Ann. Rech. Vet. II, 445

Kende M., Gainer J., Chirigos M., 1984. Chemical Regulation of Immunity in Veterinary Medicine. Alan R. Liss. Inc., NY

Michal J.J., Heirman L.R., Wong T.S., Chew B.P., 1994. Modulatory effects of dietary $\boldsymbol{\beta}$-carotene on blood and mammary leucocyte function in periparturient dairy cows. J. Dairy Sci. 77, 1408-1421 
Nagahata, 1987. Application of the fluorometric DNA quantitative assay using 4,6.diamine-2-phenilindole for the evaluation of lymphocyte blastogenic response. Res. Vet. Sci. 42, 331-333

National Research Council, 1987. Vitamin Tolerance of Animals. NRC-National Academy of Sciences, Washington, DC

Pérignon J.L., Bories D.M., Houllier A.M., Thuillier L., Cartier P.H., 1987. Metabolism of pyrimidine bases and nucleosides by pyrimidine-nucleoside phosphorylases in cultured human lymphoid cells. Biochim. Biophys. Acta 928, 130-136

Shalm's Veterinary Haematology, 1986. N.C. Jain (Editor). 4th Edition. Lea and Febiger, Philadelphia, pp. 240-255

Siegel H.S., 1985. Immunological responses as indicators of stress. World's Poultry Sci. J. 41, 36

SPSS for Windows, 1996. Ver. 7.5, Copyright SPSS Inc.

Torrence P.F., 1985. Biological Response Modifiers: New Approaches to Disease Intervention. Academic Press Inc., NY 